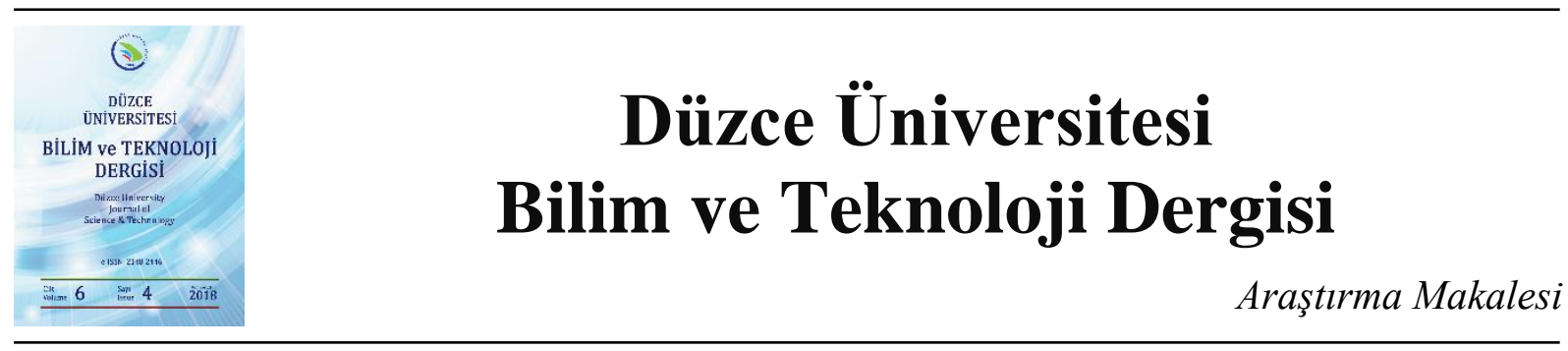

\section{BSC-MAC Protokolü Tabanlı Enerji Etkin Maden Güvenlik Sistemi}

\author{
Arafat ŞENTÜRK ${ }^{\mathrm{a},{ }^{*}}$ \\ a Bilgisayar Mühendisliği Bölümü, Mühendislik Fakültesi, Düzce Üniversitesi, Düzce, TÜRKIYE \\ * Sorumlu yazarin e-posta adresi: arafatsenturk@duzce.edu.tr
}

\begin{abstract}
ÖZET
$\mathrm{Bu}$ çalışmada, Kablosuz Algılayıcı Ağlar'ın (KAA), iletişim kurabilme, algılanan verileri iletme ve kendi aralarında kolayca organize olabilme gibi avantajlarından yararlanılmıştır. KAA'ın bu faydaları ile maden ocaklarında oluşan ve çalışan maden işçileri için hayati tehlikeye sebep olan metan gazının yoğunluğu belirlenmiştir. Belirlenen yoğunluğun, maden iş̧̧ilerini zehirlemesi veya maden ocağında patlama düzeyine gelmesi durumlarından önce uyarı vererek maden işçilerine önlem almaları için zaman kazandırmak amacı ile Maden Güvenlik Bilgi Sistemi benzetimi gerçekleştirilmiştir. Bu çalışmada bundan önce yapılmış olan maden güvenlik sistemlerine ek olarak; fazla sayıda dügüm kullanmak yerine, az sayıda ve hareket kabiliyeti kazandırılmış algılayıcı düğümler kullanılarak, harcanan toplam enerjiyi en az seviyeye indirilmesi sağlanmıştır. Ayrıca, BSC-MAC protokolü kullanılarak kullanılan toplam enerjinin IEEE 802.15.4 protokolüne göre daha az seviyeye getirilmesi sağlanmıştır. Çalışma kapsamında, Kablosuz Yer altı Algılayıcı Ağlar (KYAA) alanında yapılan çalışmalar incelenmiştir. Bu çalışmanın amacına uygun olarak KYAA'ın maden ocaklarında ne şekilde ve hangi uygulamalarda kullanıldıkları ele alınmış ve elde edilen sonuçlara göre daha uygun bir sonuç önerilmiştir. Önerilen çalışma için Network Simulation-2 (NS-2)'de farklı topolojiler kullanılarak benzetim gerçekleştirilmiş ve elde edilen sonuçlar açıklanmıştır.
\end{abstract}

Anahtar Kelimeler: Kablosuz Algılayıcı Ağlar, Yer altı Ağları, BSC-MAC, Maden güvenlik sistemi

\section{BSC-MAC Protocol based Energy Efficient Mine Security System}

\begin{abstract}
In this study, some advantages of Wireless Sensor Networks (WSN) like communication, transmission of the sensed data and easy self-organization among each other are utilized. Density of the methane gas which exists in mines and is life-critical for miners has been determined. A Mine Security System simulation has been performed to save time to miners for taking precautions as an early warning before the pre-determined density of the gas reaches to critical level that poisons the miners and causes explosion. In addition to the existing mine security systems, mobile and less number of sensor nodes have been used instead of large number of stationary nodes to minimize the total energy consumption in this study. Also, using BSC-MAC protocol provides less the energy consumption than IEEE 802.15.4 protocol. The existing studies in the field of Wireless Underground Sensor Networks (WUSN) have been examined in the scope of this paper. How and in which applications the WUSN are used in mines are tackled parallel to the purpose of this paper and an optimal solution has been
\end{abstract}




\section{GiRiș}

$\mathrm{K}$ ablosuz Yer altı Algılayıcı Ağlar (KYAA), tamamen toprak altına dağıtılır ve mevcut yöntemlere göre daha kapsamlı çalışmaktadır. KYAA, Kablosuz Algılayıcı A ğ'ların (KAA) getirdikleri faydalardan yararlanır. Ayrıca, kurulumu da basittir. Kablosuz iletişimde, verilerin aktarılması esnasında karşılaşılabilecek engellere karşı iletişimin hızı azalmamaktadır [1].

Gerçekleştirilen literatür incelemesinde KYAA ile gerçekleştirilen sistemlerde yer altındaki algılayıcı düğümlerle birçok farklı topoloji oluşturulmuş ve oldukça fazla algılayıcı düğüm kullanıldığı görülmüştür. Örneğin [2]'de düğümler maden işçilerinin kasklarına yerleştirilmiş ve işçilerin bulundukları ortamdaki gaz miktarı tespit edilmiştir. Bu çalışmada kullanılan düğüm sayısı madende çalışan işçi sayısına eşit olduğundan, çalışma alanının çok büyük olduğu ve dolayısıyla madenci sayısının da çok fazla olduğu maden ocaklarında, düğüm ve enerji maliyeti oldukça fazla olacaktır. Ayrıca, algılayıcı düğümlerin fazlalığı oluşturulan ağın trafiğinde sıkışıklığa neden olması ve gerçekleşebilecek herhangi bir hatanın belirlenmesinin zorlaşmasına sebep olması beklenmedik bir durum değildir. Ek olarak, gereksiz algılayıcı düğüm kullanılması gerçekleştirilen çalışmanın verimliliğini düşürmesi ve dügümlerin yönetimi açısından da sorun oluşturabilir. Belirlenen sorunları çözebilmek için bu çalışmada, maden ocağına kurulan raylı sistem sayesinde, algılayıcı dügümlere hareket kabiliyeti kazandırılmıştır. Böylece, kullanılan algılayıcı dügümlerin sayısı azaltılarak düğüm maliyetinin daha aza indirilmesi sağlanmıştır. Az sayıda düğüm kullanıldığında baz istasyonu ve düğ̈̈mler arasındaki trafik hafifleyeceğinden, veri akışı hızlanacak ve olumsuz durumların tespiti kolaylaşacağı ön görülmektedir. Düğümler arasında paket çakışması ve istem dışı alım gibi MAC katmanındaki problemlerin de ortaya çıkması azalabileceği düşünülmektedir. Bunlara ek olarak; gerçekleştirilen uygulamada, algılayıcı düğümlerde [3]'de geliştirilen enerji verimli BSC-MAC protokolü kullanılarak harcanan enerjinin daha da aza indirilmesi sağlanacaktır.

Çalışmanın ikinci bölümde KYAA'ların literatürdeki genel kullanım alanlarından geniş bir şekilde bahsedilmiştir. Üçüncü bölümde, kullanılan BSC-MAC protokolünden kısaca bahsedilerek, önerilen metot açıklanmıştır. Dördüncü bölümde de önerilen sistemin benzetimi ve değerlendirilmesi yapılmıştır. Beşinci bölümde ise, sonuçlar verilmiş olup, yorumlanmıştır ve daha sonrada geleceğe yönelik yapılabilecek çalışmalara değinilmiştir.

\section{II. İLgILİ ÇALIȘMALAR}

Güvenlik, yol belirleme, tarım ve jeolojik olaylar gibi uygulamaların zenginliği ile yer altı durumlarının izlenmesi için KYAA'a olan ihtiyaç gün geçtikçe artmaktadır [1], [4], [5]. 
Bölümün devamında gerçekleştirilen sisteme ve yapılan çalışmalara 1şık tutabilmesi için KYAA'ları incelenmiştir.

\section{A. KYAA'IN KULLANIM ALANLARI}

KYAA zehirli maddeleri, toprak özelliklerini, su ve mineral yoğunluğunu belirlemek ve yer altı toprak koşullarını izleyerek, uygun sulama ve gübreleme yapmak için tarımda kullanılır [1]. Doğayı korumak adına çeşitli oksit maddelerin varlığı ve yoğunluklarının izlenmesi de önemli bir uygulamadır. Bu kimyasal maddeler, nehirler ve içme suyu kaynaklarını kirletebilir. Bu gibi durumlarda, yer altı ve su altı algılayıcıların bir melez ağ kullanılması gerekecektir [1] ve bu konuda [6]'nın çalışmaları yer almaktadır. Çalışmada aynı zamanda su altı ağlarda enerji etkin yönlendirme protokolü de geliştirilmiştir.

KYAA, toprak özelliklerini izlemenin yanı sıra, toprak hareketlerini izleyerek de heyelan tahmini için kullanılabilir [7]. Heyelan tahmini için mevcut yöntemler pahalı ve zaman alıcıdır. Karasal algılayıcı dügümmler gibi yer altı algılayıcı düğümleri de ucuzdur. KYAA kullanılarak heyelanlar olmadan önce tahmin edilebilir ve etkilenen bölgelerde yaşayan insanlar erken uyarı sistemi ile haberdar olarak tahliye edilebilir. KAA buzul hareketlerini izlemek için de kullanılabilir. Dağıtılan algılayıcılar buzulların içerisindeki hareketi algılayarak veri iletebilir [8]. KYAA volkanik patlamaların önceden tahmini içinde kullanılmıştır. Yanardağın içine yerleştirilen algılayıcılar sayesinde içerideki sıcaklığın belirli seviyeye geldiği zaman uyarı sistemi devreye girmektedir [9]. Deprem izleme ve tahmininde KYAA teknolojisi ile kolaylaştırılabilir. Yüzeye yakın toprak hareketi, heyelan veya deprem tahmini için yararlı olabilir. KYAA'ın yer altındaki yapısı, verileri bas istasyonuna yönlendirerek birbirleri arasında hızlı bir şekilde iletişim sağlayabilir [10].

KYAA boru, kablo, elektrik ve sıvı depolama tankları gibi altyapıları izlemek için de kullanılabilir. Yer altı tesisatın güzergâhı boyunca dağıtılan KYAA sayesinde kaçaklar hızlı bir şekilde tespit edilip tamiri gerçekleştirilebilir. Ek olarak, KYAA mayın izleme gibi yer altı mevcut askeri uygulamalarda da kullanılabilir [11]. Ayrıca, KYAA nesnelerin konumunu belirlemek için de kullanılabilirler. Kendi konumu belli olan sabit algılayıcılar tarafından etrafindaki nesnelerin konumlarını da bildirebilirler [1].

KYAA teknolojisi, aynı zamanda yapı çökmesi sonucunda insanları bulmak amacı ile de kullanılabilir. Cihazlar bir bina altına gömülmüş ve onların fiziksel konumu programlanarak, bir çöküş durumunda, algılayıcılar baz istasyonu ile iletişim kurarak binanın belirli bir bölümü lokalize olabilir. Bu arama kurtarmada genel bir çözüm sağlar [1]. KYAA insanların veya nesnelerin yer üstünde hareketini izlemek için kullanılabilir. Bir kişinin ya da bir cismin varlığını belirlemek için basınç veya manyetik algılayıcılar kullanılması gerekir. Bu uygulama, eve gelen davetsiz misafirleri tespit etmek amaciyla, bir binanın çevresine yer altına dağıtılır ve ticari güvenlik için kullanılabilir [12]. Algılayıcıların varlığı yer altına gömülü olduğundan gizlidir. Dolayısıyla, saldırganlar algılayıcılar hakkında bilgi sahibi olma ihtimalleri çok düşüktür, böylece güvenlik sistemini devre dışı bırakmak daha zor olacaktır. Daha büyük ölçekte, KYAA sınır devriye sistemi için çok yararlı olabilir. Bir sınır uzunluğu boyunca yerleştirilmiş kablosuz basınç algılayıcıları yasadışı geçişlerde yetkilileri uyarmak için kullanılabilir. Bu sayede konum bilgileri ile programlanmış olan algılayıcılar ile yasadışı geçişin yeri kolayca tespit edilebilir ve gönderilen veri ile yetkililerle iletişime geçebilirler [13]. 


\section{BSC-MAC PROTOKOLÜ VE ÖNERILEN METOT}

Çalışmanın bu bölümünde öncelikle enerji verimliliği için kullanılan BSC-MAC protokolünden bahsedilmiş daha sonra da maden ocakları için önerilen metot detaylı olarak açıklanmıştır. Son olarak ise elde edilen sonuçlar değerlendirilmiştir.

\section{A. BCS-MAC PROTOKOL $\ddot{U}$}

BSC-MAC algılayıcı düğümler için MAC katmanında enerji verimliliği üzerine geliştirilmiştir. $\mathrm{Bu}$ katmanda enerji verimliliği üzerine yapılan çalışmalar arasında IEEE 802.15.4 protokolüne ve diğer protokollere göre daha fazla enerji verimliliği sağladığı görülmüştür. BSC-MAC protokolü enerji verimliliği için iki yöntem kullanmaktadır. Bunlar kök düğüm ve kaynak düğüm olarak belirlenmiştir. BSC-MAC'te oluşturulan kaynak düğümler, ilgili verileri algılayıp baz istasyonu tarafından belirlenen kök dügüumler aracılığıyla baz istasyonuna iletirler. BSC-MAC'te kök ve kaynak düğümler kendi aralarında olan veri iletişiminin durmaması için uyuma ve uyanma durumlarını zaman aralıkları ile uyarlamalı olarak iki farklı yöntemle kullanmaktadırlar. Baz istasyonu kök düğümlerin hangi düğüm olacağına kendi üzerinde çalıştırdığı bir algoritmayla karar vermektedir. Kök düğüm haricinde kalan düğümler ise kaynak düğüm olarak çalışmaktadır. BSC-MAC'te kök düğümlerin uyuma ve uyanma periyotlarının ayarlanması ve bu dügümlerin haberdar edilmesi baz istasyonu tarafından ayarlanmaktadır. Kök olmayan diğer düğümler ise yolu ele geçirmek için rekabet etmekte ve yolu ilk ele geçiren düğüme iletime devam etmekte iken diğer düğümler uyku moduna otomatik olarak geçmektedir. Bu sayede algılama işini devamlı yapan kaynak düğümler için aynı kapsama alanında olan düğümlerde sadece bir düğüm çalışmakta ve bu sayede diğer düğümlerin enerjisinin korunumu gerçekleştirilmektedir. Uyuma ve uyanma aralıklarının dinamik olarak baz istasyonu tarafından ayarlanan kök dügü̈mler ise kaynak düğüme benzer şekilde enerji korunumunu kendi aralarında sağlamaktadır. Buradaki en büyük avantaj ise her zaman algılama işleminin yapılıp tek bir yol üzerinden baz istasyonuna gönderilmesidir. Dolayısıyla bu katmanda yapılan diğer protokollerden enerji verimliliği ve gecikme açısından daha iyi sonuç verdiği görülmüştür [3]. Şekil 1'de BSC-MAC protokolünün iletim durumu gösterilmektedir. Burada B ile simgelenen düğüm Baz istasyonunu, $\mathrm{n}$ ile simgelenen dügümler Kök düğümleri ve $T$ ile simgelenen düğümler ise Kaynak düğümleri ifade etmektedir.

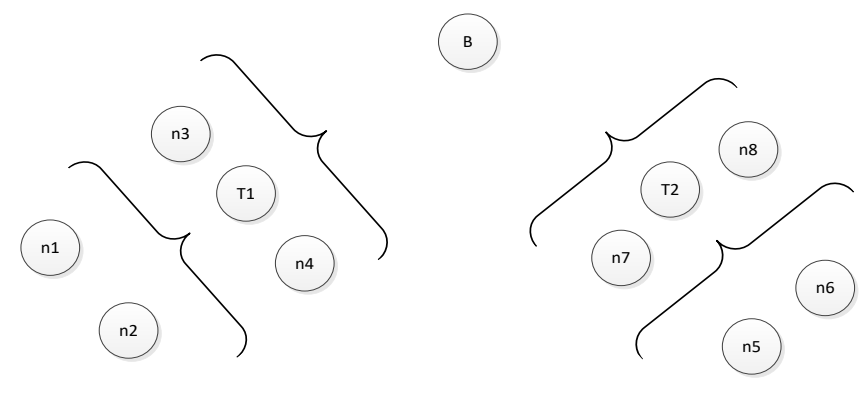

Şekil 1. BSC-MAC iletim modeli [3].

Şekil 1'de görüldüğü gibi kök düğüm mantı̆̆ıyla normal düğümlerde algılayıcı ağlarda kullanılan tepe düğüm sistemiyle çalışabilmektedirler. Bu sayede topoloji katmanlara ayrılmış ve yönetimi daha kolay hale getirilerek, uyuma ve uyanma sistemi kullanılarak düğümlerden en iyi kazanç elde edilmiştir. Ayrıca topolojilerin seviyelere ayrılması ile dügümlerin enerji verimliliği de arttırılmıştır. 


\section{B. MADEN GÜVENLIK SISTEMI ICCIIN ÖNERILEN METOT}

S. Toklu ve ark. tarafından hazırlanan çalışmada [3], BSC-MAC protokolü diğer protokollerle karşılaştığında enerji verimliliği açısından daha iyi olduğu görülmüştür. Bu çalışma incelenerek geliştirilen uygulamanın algılayıcı dügümmlerine de BSC-MAC protokolü eklenmiştir. Buna ek olarak, [14]'de gerçekleştirdiğimiz maden güvenlik sistemindeki metot ve benzetim üzerinde çalış1lmıştır ve 100 adet sabit algılayıcı düğüm yerine madenin içerisinde özel olarak tasarlanmış raylı sistem üzerinde hareket eden 10 adet algılayıcı düğüm kullanılmıştır. Hareketli sistem, algılayıcı düğümlerin benzetim süresi boyunca madencilerin çalıştıkları bütün alanlara ulaşabilecek şekilde konumlandırılmıştır ve belirlenen bu koordinatlar arasında hareket etme kabiliyeti sağlamıştır. Düğümleri hareket hızları sabit olarak ayarlanmıştır ve hareket kabiliyetlerini sergilerken fazladan harcadıkları enerji dördüncü bölümde belirtilmiştir. Ayrıca, çalışmanın karşılaştırılması olan [14]'deki çalışmada olduğu gibi algılayıcı düğümler belirli zaman aralıklarında ölçüm sağlamaktadırlar.

Ek olarak, düğümlerin hareketli olması ve dügümlere BSC-MAC protokolünün eklenmesinin sebebi, maden ocağında ulaşılamayacak, riski yüksek bölgelerde veya çökme halinde madencilerin konumunu belirlemek için ağın ömrünün en yüksek seviyede olmasını sağlamaktır. Bu sistemde, iki kaynak düğüm (T) olduğunda birinin bozulma veya yaşam ömrünün bitmesi durumunda diğeri iletişime devam edecektir. Bu sayede, iletişim kopukluluğu da olmayacaktır. Şekil 2'de BSC-MAC protokollü düğümlerin örnek bir topolojisi gösterilmektedir. Bu topolojide BSC-MAC protokolü kök ve kaynak düğümler olarak ikiye ayırdığından ortak yolu kullanan düğümler kök düğüm olarak belirlenmektedir. Örneğin n1, n2, n4, n5 ve n7 dügü̈mleri paketlerini n6 üzerinden göndereceğinden n6 düğümü burada kök dügüum olarak ayarlanmaktadır. Bu şekilde ortak yol üzerinde olan düğümler kök dügüm diğer dügümler ise kaynak dügüm olarak baz istasyonu (B) tarafindan belirlenmiştir.

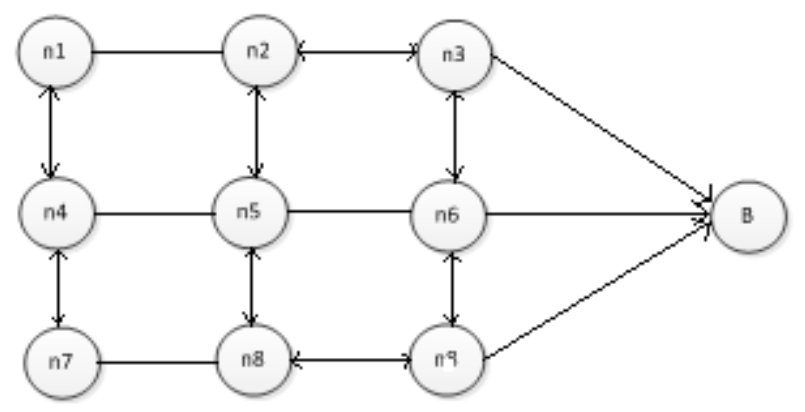

Şekil 2. Örnek bir topoloji.

Şekil 3'de ise bu örnek topolojiye göre BSC-MAC protokolünün görevi gereği düğümlerin iletim modeli gösterilmektedir. Gösterildiği gibi örnek topolojideki düğ̈̈mlerden n3, n6, n8 ve n9'un kök düğüm olduğunu varsayalım, bu durumda diğer düğümlerde kaynak düğüm olmaktadır. Bu düğümler, kapsama alanlarından çıkmamak koşuluyla düğümlerin uyuma ve uyanması BSC-MAC protokolüne göre olacağından bas istasyonunu aktif şekilde devamlı bir yol olacaktır. Bu sayede istem dışı alım ve paket çakışmaları önlenecektir. Ayrıca, maden ocağından bas istasyonuna sürekli bir veri akımı olacağından iletişim kopukluluğu söz konusu değildir. 


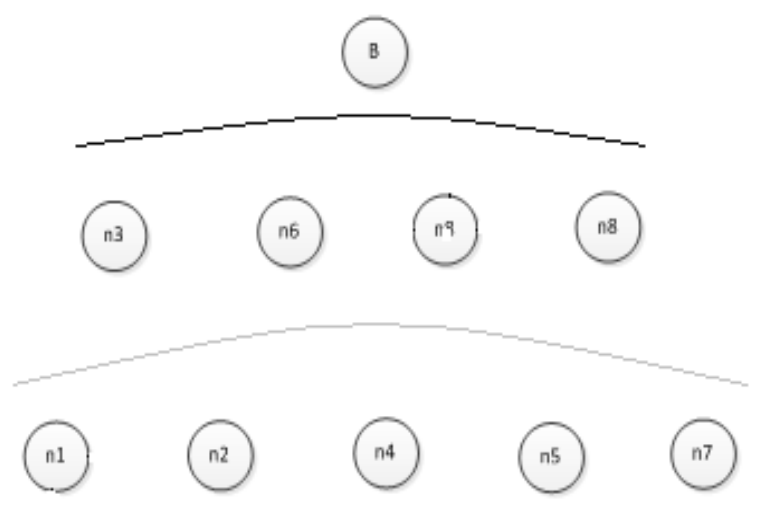

Şekil 3. Örnek topolojinin iletim modeli.

\section{IV. ÖNERILEN SISTEMIN BENZETIMİ VE DEĞERLENDIRILILMESI}

Gerçekleştirilen çalışmada, Network Simulation-2 (NS-2) kullanılmıştır. Tablo 1'de gerçekleştirilen benzetimdeki değişkenler ve bu değişkenlerin değerleri gösterilmiştir.

Tablo 1. Benzetimde kullanilan değiş̧kenler ve değerleri

\begin{tabular}{cc}
\hline Değişken & Değer \\
\hline Başlangıç Enerjisi & 100 Joule \\
İletim Gücü & 0.5 Watt \\
Alım Gücü & $0.3 \mathrm{Watt}$ \\
Boş Güç & $0.05 \mathrm{Watt}$ \\
Bant Genişliği & $0.5 \mathrm{Kpbs}$ \\
Veri cwnd & $63 \mathrm{~ms}$ \\
\hline
\end{tabular}

İlk olarak maden ocağına 100 adet sabit konumlu ve IEEE 802.15.4 protokollünü kullanan algılayıc1 düğümler yerleştirilmiştir. Yerleştirilen algılayıcı dügümler hem birbirleri hem de baz istasyonu ile aynı anda iletişim kurabilmektedirler. Benzetimde, algılayıcı düğümlerin konumu en fazla alana yayılma ve en az algılayıcı düğüm kullanılacak şekilde planlanmıştır. Daha sonra bu algılayıcı dügümlerin toplamda harcadıkları enerji değerleri hesaplanmıştır. Karşılaştırmaların daha objektif yapılabilmesi için [14]'deki çalışmamızda gerçekleştirdiğimiz benzetimin parametrelerini ve hareketli olan algılayıcı düğümlerin aynı yolu izlemeleri sağlanmıştır.

Şekil 4'de 100 adet kısmen sabit konumlu ve IEEE 802.15.4 protokolünü kullanan düğümlerin sistem benzetim çıtısı yer almaktadır. 


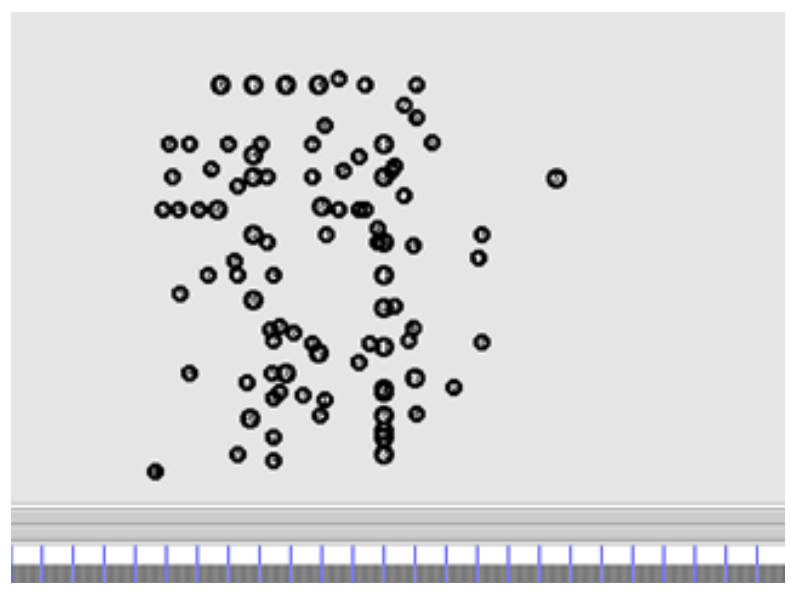

Şekil 4. 100 adet kismen sabit konumlu ve IEEE 802.15.4 protokolünü kullanan dügümlerin sistem benzetimi.

Şekil 4'de görüldüğü gibi 802.15.4 protokollü düğümlerde, yoğunluk olan bölgelerde hem paket çakışması hem de istem dışı alım çok fazla olacağı tahmin edilmektedir. Bu yüzden enerji verimliliği açısından BSC-MAC protokolü kullanılmıştır. Ayrıca, BSC-MAC protokolü kullanılması sayesinde; baz istasyonuna çok fazla şekilde benzer verinin gelmesi veya paket çakışmasından dolayı meydana gelecek karmaşıklıkta düğüm sayısının aza indirilmesi sağlanmıştır.

Önerilen yapıda, aynı alanı içeren bölgeye, 10 adet hareketli ve BSC-MAC protokolü kullanan dügümmler yerleştirilmiştir. Benzetimin çıktıları Şekil 5'de verilmiştir.

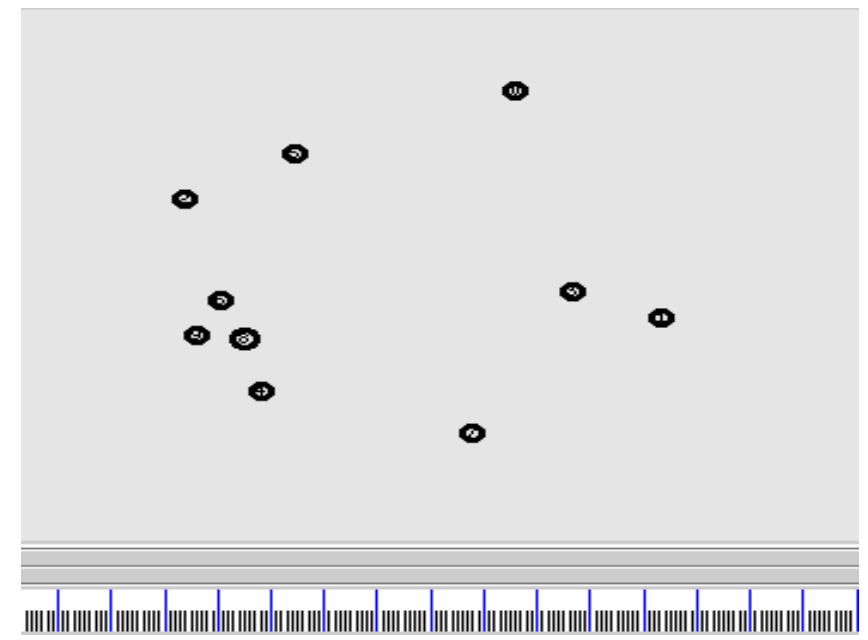

Şekil 5. Hareketli dügümlerin ilk konumlarl

10 adet hareketli düğümlerin Şekil 5'de ilk konumları, Şekil 6'da ise son konumlarını göstermektedir. Algılayıcı düğümler önceden planlanan ilk konum ve son konum arasında hareketlidir. Bu hareketli algılayıcılar 100 adet sabit konumlu algılayıcı düğümün kapsadığı alanını kapsamaktadır. 


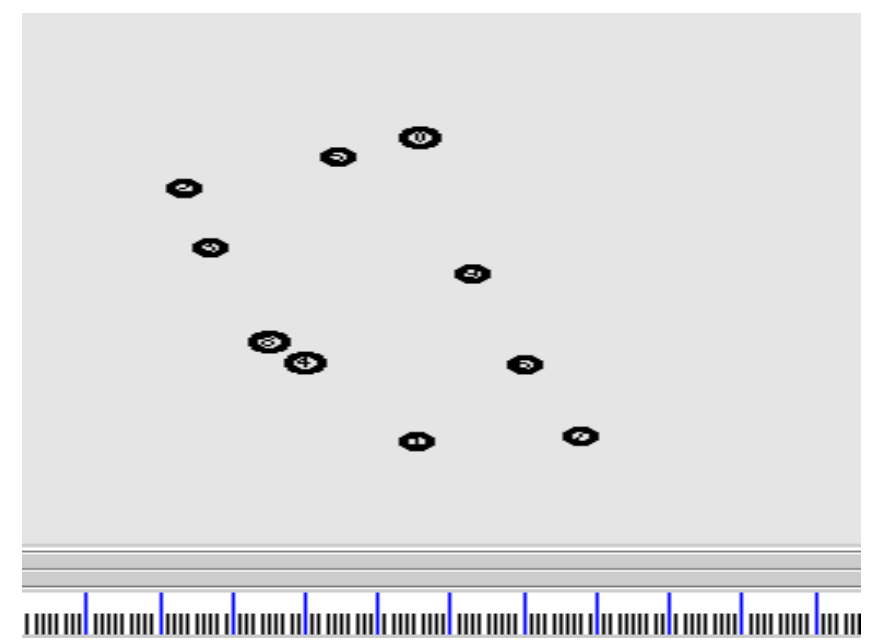

Şekil 6. Hareketli düğ̈̈mlerin son konumlart.

Benzetim yaparken 10 adet hareketli BSC-MAC protokolüne sahip düğüm ve 10 adet kısmen sabit IEEE 802.15.4 protokolüne sahip düğüm kullanılmıştır. Daha önceki kısımda bahsettiğimiz gibi, orta seviyeli bir maden ocağında en az 100 adet kısmen sabit konumlu dügüm kullanılabileceği varsayılmıştır. Ancak, kıyaslama yaparken sistemin ölçülebilirliğini ve gerçekliğini arttırmak için eşit sayıda düğüm yani 10 'ar adet düğüm kullanılmıştır. Eğer 10 adet hareketli BSC-MAC protokolü kullanan düğümler, 10 adet kısmen sabit IEEE 802.15.4 protokollünü kullanan düğümlere göre enerji verimi sağlarsa, 100 adet kısmen sabit IEEE 802.15 .4 protokollü düğ̈mlere de sağlayacağı açıktır. Benzetim sonuçları bölümünde de zaten bu ispatlanmıştır.

\section{A. BENZETIM SONUÇLARI}

Gerçekleştirilen benzetim işlemi 2000 saniye boyunca devam etmektedir. Benzetim süresince 10'ar adet algılayıcı dügümün harcanan enerji değeri, protokol bazında ve hareket durumlarına göre karşılaştırılması Tablo 2‘de, grafiği ise Şekil 9‘da yer almaktadır.

Tablo 2. Toplamda harcanan enerjinin karşılaştırılması.

\begin{tabular}{cc}
\hline $\begin{array}{c}\text { Hareketli - BSC-MAC } \\
\text { 10 Adet Düğüm }\end{array}$ & $\begin{array}{c}\text { K1smen Sabit - IEEE 802.15.4 } \\
\text { 10 Adet Dügüm }\end{array}$ \\
\hline 248 Joule & 482 Joule \\
\hline
\end{tabular}

Tablo 2'de ve Şekil 7'de toplam harcanan enerjiyi göstermektedir. Görüldüğü üzere 10 adet hareketli ve BSC-MAC protokolünü kullanan algılayıcı düğümlerin harcadıkları toplam enerji, 10 adet kısmen sabit ve IEEE 802.15.4 protokolünü kullanılan düğümlerin harcadıkları enerjinin nerdeyse yarısı kadardır. Dolayısıyla, 100 adet kısmen sabit konumlu düğümün harcadığı enerjinin toplamı çok daha fazla olacağı açıktır. 


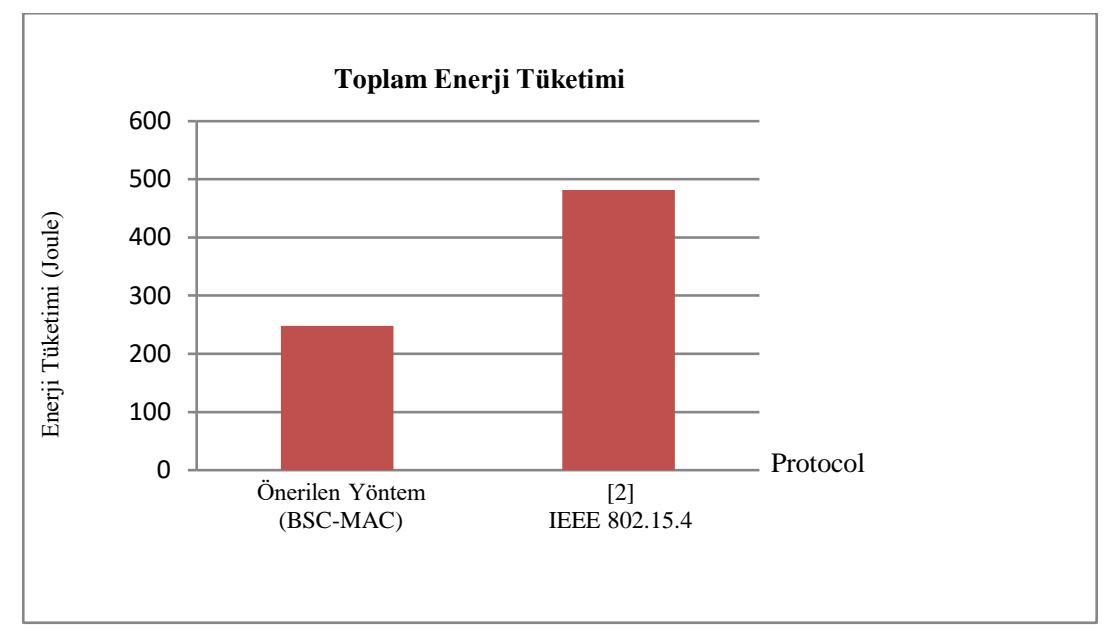

Şekil 7. Toplamda harcanan enerji grafiği.

Gerçekleştirilen benzetimde hareketsiz 100 düğüm ile yapılan iş, hareketli 10 düğüm ile yapılmaktadır. Tablo 2'de, gerçekleştirilen uygulamanın sonucunda "Hareketli ve BSC-MAC protokolü barındıran 10 adet düğüm" ve "Kısmen Sabit ve IEEE 802.15.4 protokolü barındıran 10 adet düğüm"ün harcadıkları toplam enerji karşılaştırılmıştır. Bu çalışma [14]'deki çalışmanın üzerine karş1laştırma olarak gerçekleştirilmiştir. [14]'deki çalışmada 100 adet düğüm, bu çalışmada ise 10 adet düğüm kullanılmıştır. Yani, Tablo 2'de de görüldügü üzere [14]'deki çalışmaya nazaran hem 10 adet düğüm kullanılmış hem de [3]'deki çalışmada IEEE 802.15.4 protokolüne göre enerji tasarrufu ispatlanmış olan BSC-MAC protokolü kullanılmıştır. Tablo 2'de de belirtildiği üzere, uygulama sonucunda harcanan enerjiler şu şekildedir; "Kısmen Sabit ve IEEE 802.15.4 protokolü barındıran 10 adet düğüm”ün harcadığ 1 enerji 482 joule, 100 adette ise 4820 joule'dür. "Hareketli ve BSC-MAC protokolü barındıran 10 adet düğüm’ün harcadığı enerji 248 joule'dür.

Hareketli düğümler benzetim süresi boyunca (2000 saniye) maden ocağı içerisinde belirlenen koordinatlar arasında hareket kabiliyetleri vardır. Hareketli sistemin benzetim süresi boyunca harcadığı enerji hesaplanmıştır. Hareketli sistemin harcadığı enerji 63 joule'dür. "Hareketli ve BSCMAC protokolü barındıran 10 adet dügüm”ün toplam harcadığı enerji 311 joule'dür. Dolayısı ile elde edilen kazanç 4509 joule ile \%93,54'dür.

\section{SONUCLLAR}

$\mathrm{Bu}$ çalışmada, gerçekleştirilen uygulamanın belirlenen maden ocağının tamamını kapsaması için çok sayıda ve sabit konumda kullanılan algılayıcı düğümler yerine, hareketli kabiliyeti olan daha az sayıda algılayıcı dügümünler kullanılarak dügüm ve toplam enerji maliyetinin düşürülmesi sağlanmıştır. Buna ek olarak kullanılan düğümlerde, BSC-MAC protokolü kullanılarak bu protokolün özellikleri sayesinde toplamda tüketilen enerji, IEEE 802.15.4 protokolüne göre oldukça az seviyeye getirilmesi sağlanmıştır.

Önerilen maden güvenlik sistemi sayesinde, toplam enerjinin ve düğ̈̈m sayısının oldukça azaldığ1 görülmektedir. Enerjinin az harcanması ile ağın ömrü de daha uzun olacağı açıktır. Bu sayede sistemin güvenliği de arttırılmıştır. Ayrıca, sistemde daha az düğüm kullanılmasından dolayı paket trafiği ve çakışmalarında daha az olacağı ön görülmektedir. 
Bu çalışmanın devamı olarak hareket eden düğümlerin ilk ve son konumları arasındaki izledikleri yolu daha verimli geçirmeleri için, yani dügümlerin gereksiz hareket ederek enerji harcamamaları için, bir algoritma geliştirilebilir ve bu sayede enerji kullanımı daha da verimli hale getirilebilir.

\section{KAYNAKLAR}

[1] I. F. Aky1ldiz, E. P. Stuntebeck, "Wireless underground sensor networks: Research challenges". Ad Hoc Networks, vol. 4, no. 6, pp. 669-686, 2006.

[2] C. Qiang, S. Ji-ping, Z. Zhe, Z. Fan, “ZigBee Based Intelligent Helmet for Coal Miners”. WRI World Congress on Computer Science and Information Engineering, Los Angeles, California USA, 2009.

[3] S. Toklu, O. Ayhan Erdem, "BSC-MAC: Energy efficiency in wireless sensor networks with base station control”, Computer Networks, vol. 59, pp. 91-100, 2014.

[4] The Advanced Aeration Group, (2018 10 Mart), "Gelişmiş Havalandırma Grubu”. Erişim: http://www.advancedaeration.com.

[5] V. Parameswaran, H. Zhou, Z. Zhang, "Irrigation control using Wireless Underground Sensor Networks". Sixth International Conference on Sensing Technology (ICST), Kolkata, West Bangal, India, 2012.

[6] W. Longkang, N. Baisheng, Z. Ruming, Z. Shengrui, L. Hailong, "Zigbee-Based Positioning System For Coal Miners”. Procedia Engeniring, vol. 26, pp. 2406-2414, 2011.

[7] A. Sheth, K. Toyama, K. Tejaswi, P. Mehta, C. Parekh, R. Bansal, S. Merchant, T. Singh,U. B. Desai, C.A. Thekkath, "SenSlide". Proceedings of the 3rd international conference on Embedded networked sensor systems-SenSys, USA, 2005.

[8] K. Martinez, R. Ong, J. Hart, "Glacsweb: a sensor network for hostile environments". First Annual IEEE Communications Society Conference on Sensor and Ad Hoc Com. and Networks, Santa Clara, California, 2004.

[9] G. Werner-Allen, K. Lorincz, M. Ruiz, O. Marcillo, J. Johnson, J. Lees, M. Welsh, "Deploying a wireless sensor network on an active volcano". IEEE Internet Computer, vol. 2, no. 10, pp. 18-25, 2006.

[10] H. Zemmour, G. Baudoin, A. Diet, "Soil Effects on the Underground-to-Aboveground Communication Link in Ultrawideband Wireless Underground Sensor Networks". IEEE Antennas Wirel. Propag. Lett., vol. 16, pp. 218-221, 2017.

[11] G. E. Rolader, J. Rogers, J. Batteh, “Self-healing minefield”. 2004. 
[12] S. Kisseleff, X. Chen, I. F. Aky1ldı, W. H. Gerstacker, "Efficient Charging of Access Limited Wireless Underground Sensor Networks". IEEE Trans. Commun., vol. 64, no. 5, pp. 2130 $2142,2016$.

[13] Z. Sun, I. F. Akyıldı, G. P. Hancke, "Dynamic Connectivity in Wireless Underground Sensor Networks”. IEEE Trans. Wirel. Commun., vol. 10, no. 12, pp. 4334-4344, 2011.

[14] A. Senturk, Z. K. Senturk, "Hareketli Kablosuz Yeralti Algilayici Aglar Kullanilarak Enerji Etkin Maden Guvenlik Sistemi Gelistirilmesi”, SAU Fen Bilim. Enstitüsü Dergisi, s. 19, c. 3, ss. 321-325, 2015. 